BioMedical Engineering

OnLine

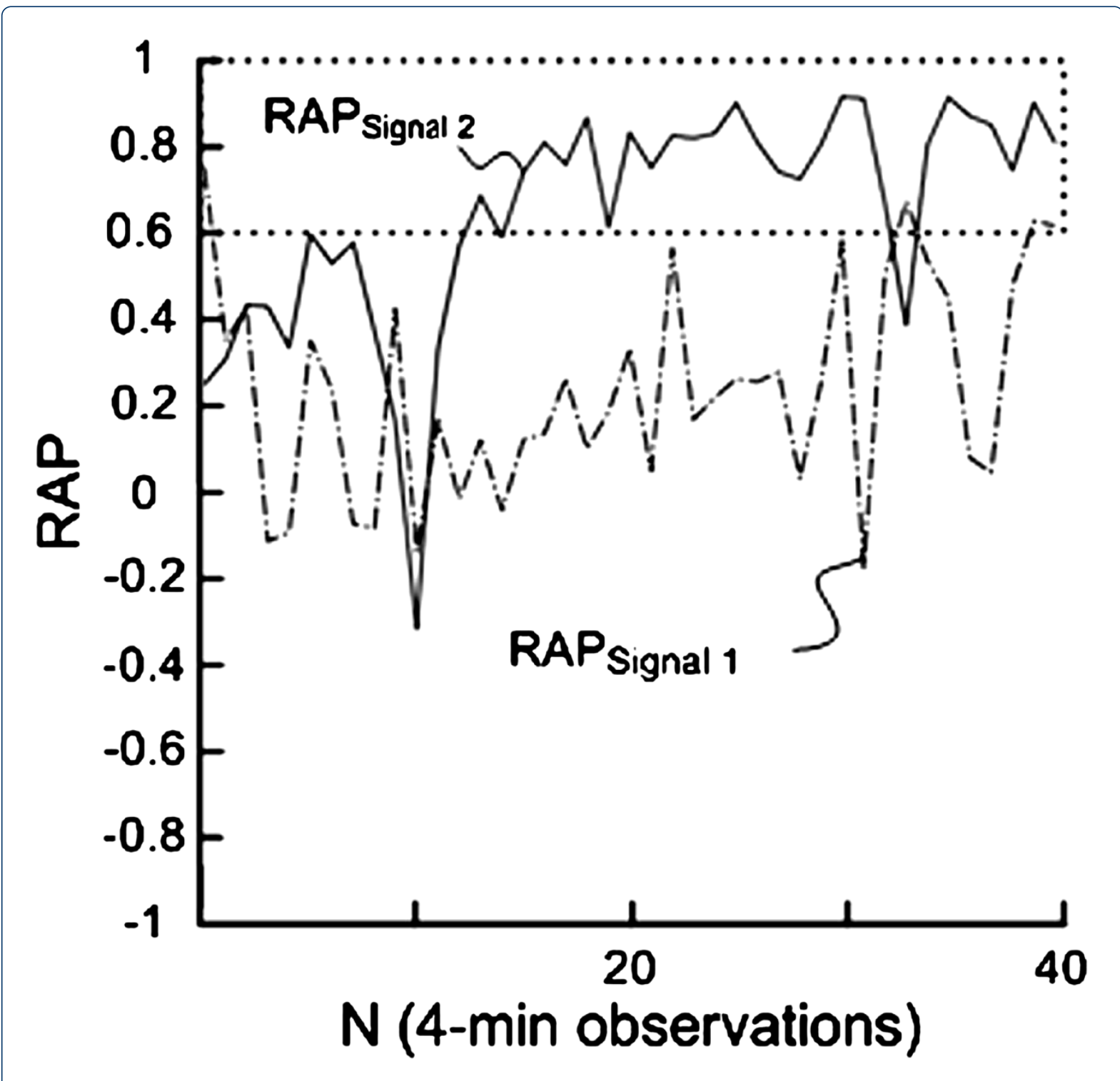

An intracranial pressure-derived index monitored simultaneously from two separate sensors in patients with cerebral bleeds: comparison of findings

Eide and Sorteberg

() Biomed Central

Eide and Sorteberg BioMedical Engineering OnLine 2013, 12:14 


\section{An intracranial pressure-derived index monitored simultaneously from two separate sensors in patients with cerebral bleeds: comparison of findings}

Per Kristian Eide ${ }^{1,2^{*}}$ and Wilhelm Sorteberg ${ }^{1}$

\footnotetext{
* Correspondence: peide@ous-hf.no 'Department of Neurosurgery, Oslo University Hospital, Rikshospitalet, Oslo, Norway

${ }^{2}$ Faculty of Medicine, University of Oslo, Oslo, Norway
}

\begin{abstract}
Background: In an attempt to characterize the intracranial pressure-volume compensatory reserve capacity, the correlation coefficient (R) between the ICP wave amplitude (A) and the ICP (P) level (RAP) has been applied in the surveillance of neurosurgical patients. However, as the ICP level may become altered by electrostatic discharges, human factors, technical factors and technology issues related to the ICP sensors, erroneous ICP scores may become revealed to the physician, and also become incorporated into the calculated RAP index. To evaluate the problem with regard to the RAP, we compared simultaneous RAP values from two separate ICP signals in the same patient.
\end{abstract}

Materials and Methods: We retrieved our recordings in 20 patients with cerebral bleeds wherein the ICP had been recorded simultaneously from two different sensors. Sensor 1 was always a solid sensor while sensor 2 was a solid sensor (Category A), a fluid sensor (Category B), an air-pouch sensor (Category C), or a fibreoptic sensor (Category D). The simultaneous signals were analyzed with automatic identification of the cardiac induced ICP waves, with subsequent determination and comparison of the Pearson correlation coefficient between mean wave amplitude (MWA) and mean ICP (RAP) for 40 6-s time windows every 4-min period.

Results: A total of 23,056 4-min RAP observations were compared. A difference in RAP $\geq 0.4$ between the two signals was seen in $4 \%$ of the observations in Category A-, in $44 \%$ of observations in Category B -, in $20 \%$ of observations in Category C -, and in $28 \%$ of observations in Category $D$ patients, respectively. Moreover, the combination of a RAP of $<0.6$ in one signal and $\geq 0.6$ in the other was seen in $>20 \%$ of scores in 3/5 Category A -, in 3/5 Category B -, in 5/7 Category C - and 1/3 Category D patients.

Conclusions: Simultaneous monitoring of the ICP-derived index RAP from two separate ICP sensors reveals marked differences in the index values. These differences in RAP may be explained by erroneous scoring of the ICP level. This will hamper the usefulness of RAP as a guide in the management of neurosurgical patients. 


\section{Introduction}

Monitoring of the intracranial pressure (ICP) remains a cornerstone in the intensive care management of neurosurgical patients [1-3]. Besides scoring the level of ICP (mean ICP), monitoring of the cardiac-induced ICP waves has lately received attention [4-6]. The management goal is then to keep the mean ICP $<20-25 \mathrm{mmHg}[1,7]$, or the mean ICP wave amplitude (MWA) $<5 \mathrm{mmHg}$ [5]. In an attempt to characterize the intracranial pressure-volume compensatory reserve capacity some authors have in addition calculated ICP-derived indices $[6,8,9]$. An index measuring the correlation coefficient (R) between the ICP wave amplitude (A) and the mean ICP (P) level (referred to as RAP) has thus been applied in the surveillance of patient groups such as those suffering from traumatic brain injury (TBI), cerebral bleeds or hydrocephalus $[8,10-12]$. With an upper normal threshold level of about $+0.6[3,8,11-14]$ a RAP approaching +1 has been considered as indicative of reduced compensatory reserve capacity.

A crucial, though yet less recognized, aspect of monitoring the level of ICP is that it may become altered by electrostatic discharges in the hospital environment [15], or through human factors, technical factors and technology issues related to the ICP sensors [16]. The consequence of these changes in baseline pressure is then erroneous ICP revealed to the physician [16]. Using these erroneous ICP values when calculating an index, e.g. the RAP, one could anticipate errors being incorporated into the index as well. To see if this in fact occurs, we designed a study wherein simultaneous RAP values derived from two separate ICP sensors in the same patient were compared. The concept of simultaneous measurements from two separate sensors in the same patient was used because erroneous ICP values usually do not become introduced at the same time in both sensors [16]. To this end, and with special emphasize on differences in RAP between the two signals, ICP scores from 20 patients with cerebral bleeds wherein the ICP had been monitored simultaneously from two separate sensors were analyzed.

\section{Methods}

\section{Patient recordings}

The ICP recordings were retrieved from patients managed for aneurysmal subarachnoid haemorrhage (SAH) and/or intra-cerebral haemorrhage (ICH) at the Department of Neurosurgery, Oslo University Hospital - Rikshospitalet during the time period 2002-2011. All patients wherein management included simultaneous monitoring from two separate ICP sensors were included.

The Regional Committee for Medical and Health Research Ethics (REK) of Health Region South-East, Norway approved the study as a quality study (2010/1328). The study was also approved by the Oslo University Hospital - Rikshospitalet as a quality study $(2010 / 16315)$.

\section{ICP monitoring and analysis}

The setup for the simultaneous ICP monitoring was as follows: Sensor 1 was always a solid (strain-gauge) sensor (Codman Microsensor, Codman MicroSensor, Johnson and Johnson, Raynham, Massachusetts, USA), while Sensor 2 was either (a) another solid sensor (Codman Microsensor, Codman MicroSensor, Johnson and Johnson, Raynham, 
Massachusetts, USA; Category A), (b) a fluid sensor (Edward's fluid sensor) connected to an external ventricular drain (Truwave PX-600F Pressure Monitoring Set, Edwards Life sciences LLC, Irvine, CA, USA; Category B), (c) an air-pouch sensor (Spiegelberg intraparenchymal probe 3PN, Spiegelberg KG, Hamburg, GE; Category C), or a fibreoptic sensor (Camino OLM ICP sensor, Camino Laboratories, San Diego, CA; Category D). Both ICP sensors were implanted at the same time.

The ICP sensors were introduced to the intracranial compartment either via a small burr hole and a minimal opening in the dura or via the craniotomy used for aneurysm clipping/hematoma evacuation. The solid sensor was placed within the brain parenchyma, and connected via cable to the ICP Express (Codman ICP Express, Johnson and Johnson, Raynham, Massachusetts, USA). The fluid sensor was connected outside the patient to an external ventricular drain (EVD) that had been placed in the ventricular fluid, while the air-pouch sensor was placed in the ventricular fluid, and connected to a Spiegelberg ICP Monitor (Spiegelberg KG, Hamburg, Ge). The fibre-optic sensor was placed within the brain parenchyma, and connected via cable to the MPM-1 Camino monitor (Camino Laboratories, San Diego, CA). The ICP signals from all sensors were passed to a vital signs Siemens 9000 XL Series Monitor (Siemens Medical Systems Inc., Danvers, MA, USA). By means of the Siemens Infinity Gateway Software (Siemens Medical Systems Inc., Danvers, MA, USA), the continuous ICP signals were transferred online via the hospital network to a computer server and stored as raw data files (sampling rate $100 \mathrm{~Hz}$ ).

The analysis of the continuous ICP waveforms was done using a previously published method for automatic identification of cardiac induced ICP waves [17]. The method has been implemented in the software (Sensometrics Software, dPCom As, Oslo, Norway). Each single ICP wave becomes identified by its beginning and ending diastolic minimum pressure, and its systolic maximum pressure, and various single ICP wave parameters are determined, such as the pressure difference between the beginning diastolic and systolic pressures (dP). For 6-s time windows containing a minimum of 4 cardiac induced ICP waves, the mean ICP and the mean ICP wave amplitude (MWA) were determined.

The correlation coefficient (R) between the ICP wave amplitude (A) and ICP (P) level (RAP) was determined during consecutive 4-min time periods $[8,14]$. Thus, the RAP represents the Pearson correlation coefficient between the MWA and the mean ICP in 40 6-s time window periods. Since we compared RAP of two simultaneous ICP signals, the RAP of Sensors 1 and 2 were derived from simultaneous 6-s time windows (Figure 1a-b). For every consecutive 4-min period the software hence determined the Pearson correlation coefficient (RAP) values of the two ICP signals (Figure 1c-d). The RAP scores could then be trended as shown in Figure 2.

The Pearson correlation coefficient is a measure of the strength of a relationship between two variables and may range from -1 to +1 . A negative correlation coefficient occurs when one variable changes in the opposite direction of the other; whereas a positive correlation coefficient indicates that both variables change in the same direction (Figure 1c-d). The closer the correlation coefficient is to +1 , the stronger is the relationship between the two variables.

Based on previous findings, the assumptions for using the Pearson correlation coefficient were fulfilled: both the ICP and the MWA are continuous and independent 


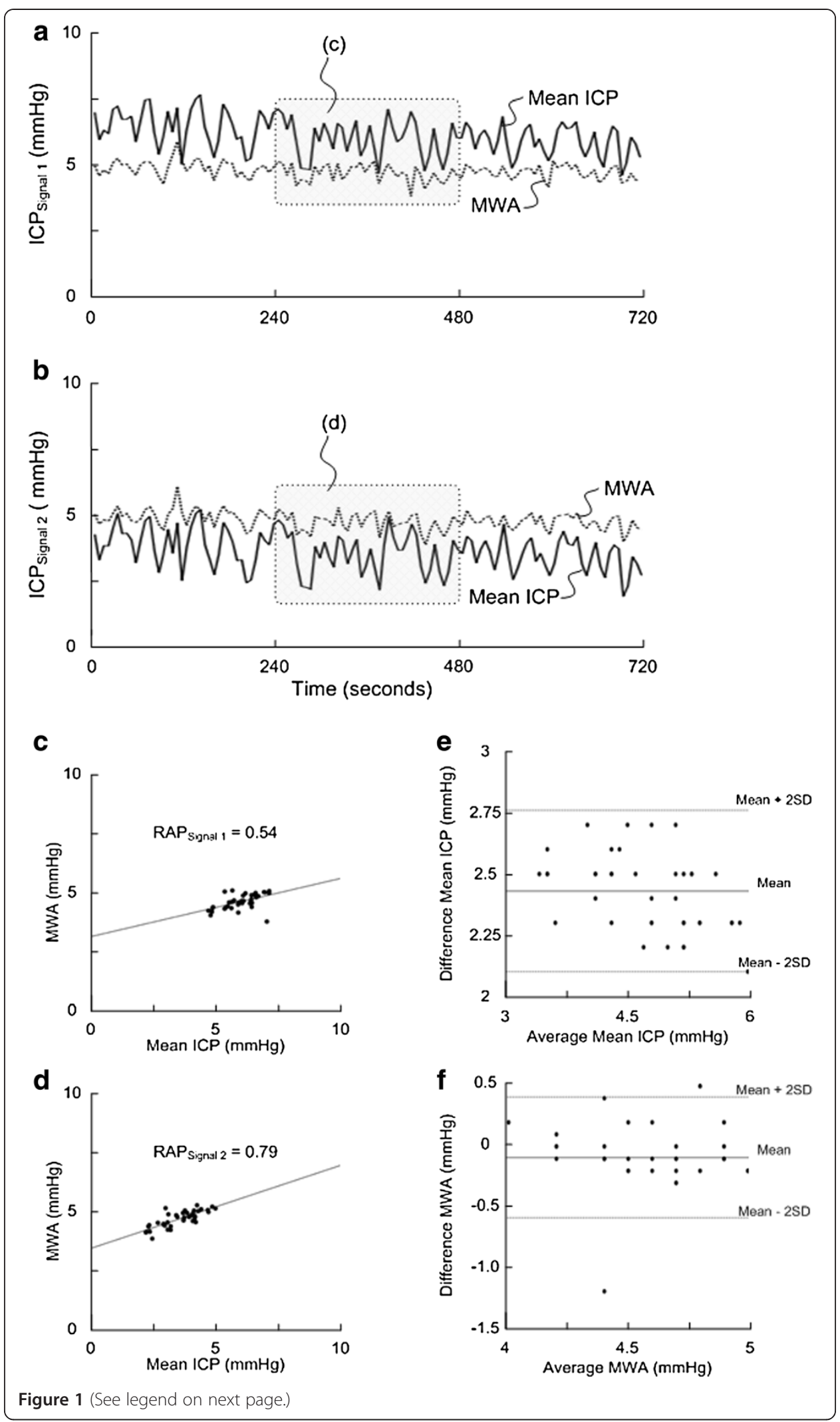


(See figure on previous page.)

Figure 1 Illustration of the method of determining the RAP in patient 1. Following automatic identification of the cardiac induced single intracranial pressure (ICP) waves, the mean ICP and mean wave amplitude (MWA) are determined for every 6-s time window. Trend plots of mean ICP and MWA determined during the same 6-s time windows are shown for Signals 1 (a) and 2 (b) over a 12 min period (representing three 4-min periods, and 120 6-s time windows). For Signal 1 (a) the average ( \pm standard deviation) of mean ICP was $6.1 \pm 0.7 \mathrm{mmHg}$ and of MWA $4.7 \pm 0.3 \mathrm{mmHg}$; while for Signal 2 (b) mean ICP 3.6 $\pm 0.7 \mathrm{mmHg}$ and MWA $4.8+0.3 \mathrm{mmHg}$ (mean difference of ICP $-2.4 \pm 0.2 \mathrm{mmHg}$; mean difference of MWA $0.09 \pm 0.17 \mathrm{mmHg}$ ). RAP is determined as the Pearson correlation coefficient between mean ICP and MWA during subsequent 4 min periods (representing 40 6-s time windows). For the 20 patients in this study, we compared the RAP values during the same 4-min periods for Signals 1 and 2. For the 4-min period shown here, RAP was 0.54 for Signal 1 (c) while 0.79 for Signal 2 (d). The difference in RAP during this 4 min period was related to the difference in mean ICP [mean ICP: $5.9 \pm 0.7 \mathrm{mmHg}$ (Signal 1) vs. $3.5 \pm 0.8 \mathrm{mmHg}$ (Signal 2)], while the difference in MWA was marginal [MWA: $4.6 \pm 0.3 \mathrm{mmHg}$ (Signal 1) vs. $4.7 \pm 0.3 \mathrm{mmHg}$ (Signal 2)]. This is further illustrated in a Bland-Altman [33] plot showing less agreement between mean ICP (e; mean difference $=2.43 \mathrm{mmHg}$; mean $+2 \mathrm{SD}=2.76 \mathrm{mmHg}$; mean $-2 \mathrm{SD}=2.10 \mathrm{mmHg}$ ), while higher agreement between MWA of Signals 1 and 2 (f; mean difference $=-0.09$ mmHg; mean $+2 \mathrm{SD}=0.41$ mmHg; mean $2 \mathrm{SD}=-0.59 \mathrm{mmHg}$.

observations that follow a normal distribution. For 4-minute intervals, the correlation coefficient between these two observations reflects a linear relationship.

\section{Results}

\section{Patient recordings}

Table 1 gives information with regard to demography, type of cerebral bleed, and the ICP sensor types and locations for the 20 patients.

\section{Simultaneous RAPs of Signal 1 and Signal 2}

Figure 1 illustrates how RAP may differ between Signals 1 and 2 due to differences in mean ICP level while MWA being close to identical.

Simultaneous RAP scores from Signal 1 and Signal 2 are presented in Table 2. Table 2, left shows the number of 4-min RAP scores in each patient. For all 20 patients combined, a total of 23,056 4-min RAP scores were analyzed. Table 2, middle presents the RAP scores (mean and \pm std) for each patient. Values $\geq 0.6$ (upper limit of normality) are highlighted. Table 2, right shows differences in RAP between Signal 1 and Signal 2 exceeding $0.2,0.4$ and 0.6 , respectively. A difference in RAP $\geq 0.4$ between the two signals was seen in $4 \%$ of the observations in Category A-, in $44 \%$ of observations in Category B -, in $20 \%$ of observations in Category C -, and in $28 \%$ of observations in Category D patients, respectively D (Table 2).

Figure 2 illustrates how the RAP could differ between Signals 1 and 2. The figure shows short trends of RAP signals in Category A- (Figure 2a), B- (Figure 2b), C(Figure 2c) and D patients (Figure 2d), respectively. This aspect is further illustrated in Figure 3, showing histograms of the differences in RAP between the two signals for all scores. Examples are presented of patients in Category A (Figure 3a), B (Figure 3b), C (Figure 3c) and D (Figure 3d), respectively.

Table 3 presents the portion of 4-min observations wherein RAP was $<0.6$ in both signal (left), $\geq 0.6$ in both signals (middle) and $<0.6$ in one signal and $\geq 0.6$ in the other (right). The combination of a RAP of $<0.6$ in one signal and $\geq 0.6$ in the other was seen in $>20 \%$ of scores in $3 / 5$ Category A patients, in 3/5 Category B patients, in 5/7 Category $\mathrm{C}$ patients and $1 / 3$ Category $\mathrm{D}$ patients, respectively. 


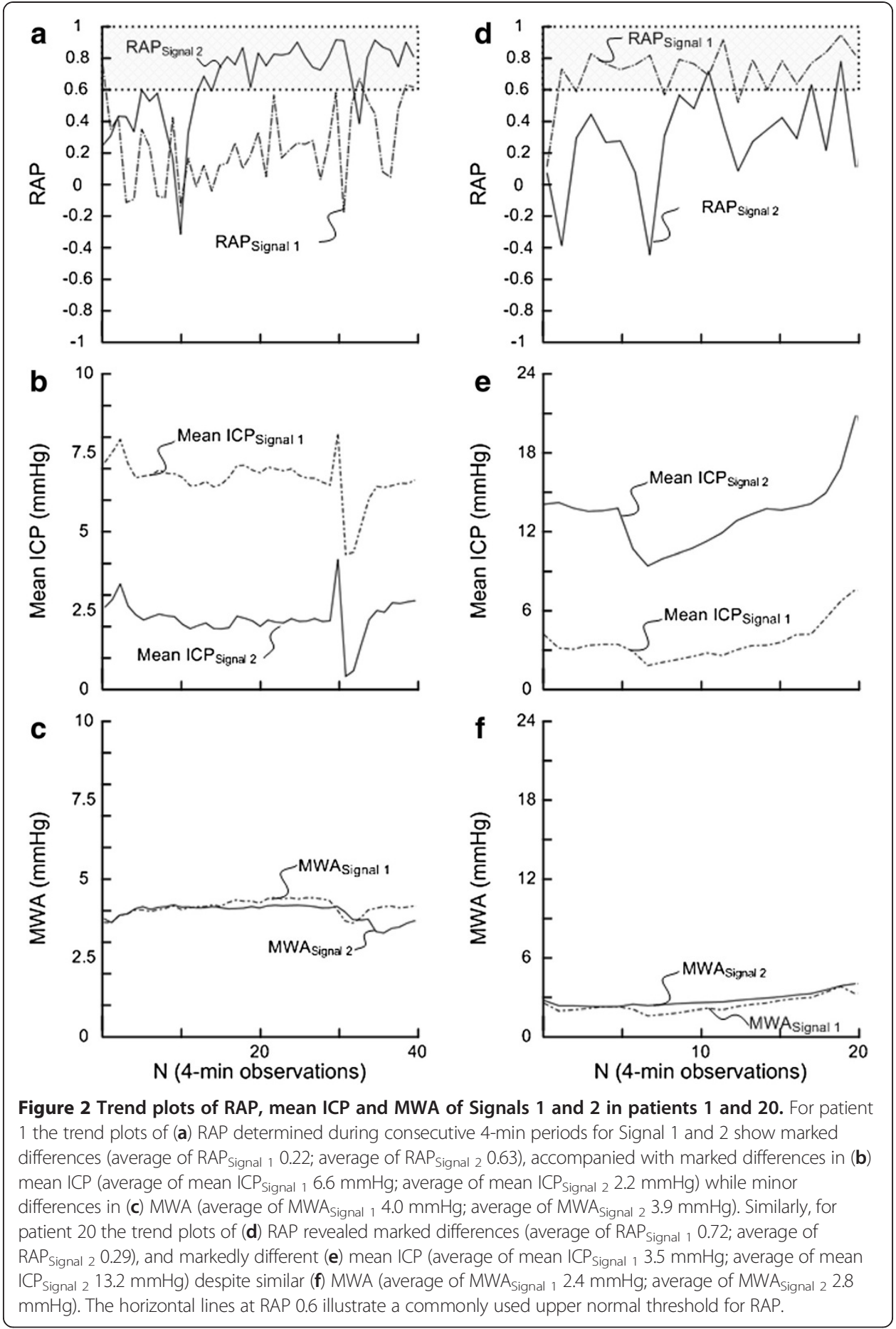

\section{Discussion}

The main finding of the present study was that simultaneous monitoring of the ICPderived index RAP from two separate ICP sensors in the same patient revealed marked differences in index values. In a setting where erroneous ICP values are introduced at separate points of time in the two sensors, this finding could be anticipated. To our knowledge, this is further the first study wherein RAP values from simultaneous ICP signals are compared. 
Table 1 Information about demography, type of bleed and ICP sensor type and location in 20 patients with cerebral bleeds

\begin{tabular}{|c|c|c|c|c|c|c|c|}
\hline \multirow[t]{2}{*}{ PatID } & \multirow[t]{2}{*}{ Age } & \multirow[t]{2}{*}{ Gender } & \multirow[t]{2}{*}{ Type of bleed } & \multicolumn{2}{|c|}{ Sensor type } & \multicolumn{2}{|c|}{ Sensor location } \\
\hline & & & & Signal 1 & Signal 2 & Signal 1 & Signal 2 \\
\hline \multicolumn{8}{|c|}{ Category A } \\
\hline 1 & 66 & M & SAH (ACOM) & Solid & Solid & Left frontal lobe & Right frontal lobe \\
\hline 2 & 76 & M & $\begin{array}{c}\mathrm{ICH} \\
\text { (right parieto-occipital) }\end{array}$ & $"$ & $"$ & Left frontal lobe & Left occipital lobe \\
\hline 3 & 39 & $\mathrm{~F}$ & SAH (ACOM) & $"$ & " & Right frontal lobe & Right occipital lobe \\
\hline 4 & 72 & $\mathrm{~F}$ & SAH (left MCA) & $"$ & " & Left frontal lobe & $\begin{array}{l}\text { Left frontal } \\
\text { ventricular horn }\end{array}$ \\
\hline 5 & 59 & $\mathrm{~F}$ & SAH (left MCA) & " & " & Right frontal lobe & $\begin{array}{l}\text { Right frontal } \\
\text { ventricular horn }\end{array}$ \\
\hline \multicolumn{8}{|c|}{ Category B } \\
\hline 6 & 56 & M & $\mathrm{SAH}(\mathrm{BA})$ & Solid & Fluid & Right frontal lobe & $\begin{array}{l}\text { Right frontal } \\
\text { ventricular horn }\end{array}$ \\
\hline 7 & 48 & M & SAH (left MCA) & " & " & Right frontal lobe & $\begin{array}{l}\text { Right frontal } \\
\text { ventricular horn }\end{array}$ \\
\hline 8 & 60 & M & SAH (ACOM) & $"$ & $"$ & Right frontal lobe & $\begin{array}{l}\text { Right frontal } \\
\text { ventricular horn }\end{array}$ \\
\hline 9 & 50 & $F$ & SAH (right VA) & $"$ & " & Right frontal lobe & $\begin{array}{l}\text { Right frontal } \\
\text { ventricular horn }\end{array}$ \\
\hline 10 & 55 & $F$ & SAH (ACOM) & " & $"$ & Left frontal lobe & $\begin{array}{l}\text { Left frontal } \\
\text { ventricular horn }\end{array}$ \\
\hline \multicolumn{8}{|c|}{ Category C } \\
\hline 11 & 66 & M & $\mathrm{ICH}$ (right frontal)/IVH & Solid & Air-pouch & Right frontal lobe & $\begin{array}{l}\text { Right frontal } \\
\text { ventricular horn }\end{array}$ \\
\hline 12 & 56 & $\mathrm{~F}$ & SAH (right MCA) & $"$ & $"$ & Right frontal lobe & $\begin{array}{l}\text { Right frontal } \\
\text { ventricular horn }\end{array}$ \\
\hline 13 & 60 & $\mathrm{~F}$ & SAH (BA/left ICA) & $"$ & " & Right frontal lobe & $\begin{array}{l}\text { Right frontal } \\
\text { ventricular horn }\end{array}$ \\
\hline 14 & 54 & M & SAH (left PCOM) & $"$ & $"$ & Right frontal lobe & $\begin{array}{l}\text { Right frontal } \\
\text { ventricular horn }\end{array}$ \\
\hline 15 & 67 & M & SAH (right PCOM) & $"$ & $"$ & Left frontal lobe & $\begin{array}{l}\text { Left frontal } \\
\text { ventricular horn }\end{array}$ \\
\hline 16 & 71 & M & ICH (cerebellum) & " & " & Right frontal lobe & $\begin{array}{l}\text { Right frontal } \\
\text { ventricular horn }\end{array}$ \\
\hline 17 & 82 & $\mathrm{~F}$ & ICH (cerebellum) & $"$ & " & Right frontal lobe & $\begin{array}{l}\text { Right frontal } \\
\text { ventricular horn }\end{array}$ \\
\hline \multicolumn{8}{|c|}{ Category D } \\
\hline 18 & 60 & $\mathrm{~F}$ & SAH (right ICA) & Solid & Fibre-optic & Right frontal lobe & Right frontal lobe \\
\hline 19 & 71 & M & SAH (ACOM) & $"$ & " & Right frontal lobe & Right frontal lobe \\
\hline 20 & 52 & $\mathrm{~F}$ & SAH (left PCOM) & " & $"$ & Right frontal lobe & Right frontal lobe \\
\hline
\end{tabular}

ACOM: anterior communicating artery; $B A$ : basilar artery; ICA: internal carotid artery; ICH: Intra-cerebral haemorrhage; IVH: intra-ventricular haematoma; $M C A$ : middle cerebral artery; $P C O M$ : posterior communicating artery; SAH: Subarachnoid haemorrhage; $V A$ : vertebral artery. 
Table 2 Comparison of RAP between Signals 1 and 2

\begin{tabular}{|c|c|c|c|c|c|c|}
\hline \multirow[t]{2}{*}{ PatID } & \multirow[t]{2}{*}{ N (4-min RAP observations) } & \multicolumn{2}{|c|}{ RAP (average + std) } & \multicolumn{3}{|c|}{$\begin{array}{c}\text { Differences in RAP between Signals } 1 \\
\text { and } 2(\mathrm{~N}, \%)\end{array}$} \\
\hline & & Signal 1 & Signal 2 & 0.2 & 0.4 & 0.6 \\
\hline \multicolumn{7}{|c|}{ Category A } \\
\hline 1 & 685 & $0.45 \pm 0.4$ & $0.42 \pm 0.39$ & $315(46 \%)$ & $162(24 \%)$ & $45(7 \%)$ \\
\hline 2 & 1,040 & $0.37 \pm 0.22$ & $0.36 \pm 0.22$ & $105(10 \%)$ & $6(1 \%)$ & 1 \\
\hline 3 & 414 & $0.83 \pm 0.17$ & $0.78 \pm 0.21$ & $52(13 \%)$ & $18(4 \%)$ & $7(2 \%)$ \\
\hline 4 & 604 & $0.58 \pm 0.29$ & $0.65 \pm 0.28$ & $115(19 \%)$ & $23(4 \%)$ & $8(1 \%)$ \\
\hline 5 & 1,065 & $0.57 \pm 0.38$ & $0.59 \pm 0.36$ & 419 (39\%) & $206(19 \%)$ & $78(7 \%)$ \\
\hline \multicolumn{7}{|c|}{ Category B } \\
\hline 6 & 211 & $0.55 \pm 0.39$ & $-0.74 \pm 0.20$ & 207 (98\%) & 201 (95\%) & $190(90 \%)$ \\
\hline 7 & 1,499 & $0.56 \pm 0.35$ & $0.11 \pm 0.58$ & $1,060(71 \%)$ & $838(56 \%)$ & $673(45 \%)$ \\
\hline 8 & 274 & $0.67 \pm 0.37$ & $0.28 \pm 0.67$ & $140(51 \%)$ & $95(35 \%)$ & $70(26 \%)$ \\
\hline 9 & 191 & $0.09 \pm 0.43$ & $0.13 \pm 0.43$ & 130 (68\%) & 84 (44\%) & 44 (23\%) \\
\hline 10 & 302 & $0.88 \pm 0.13$ & $0.86 \pm 0.14$ & $61(20 \%)$ & $17(6 \%)$ & 1 \\
\hline \multicolumn{7}{|c|}{ Category C } \\
\hline 11 & 1,834 & $0.62 \pm 0.27$ & $0.80 \pm 0.17$ & 844 (46\%) & 347 (19\%) & 129 (7\%) \\
\hline 12 & 4.777 & $0.15 \pm 0.29$ & $0.16 \pm 0.28$ & $2,661(56 \%)$ & 1,135 (24\%) & 427 (9\%) \\
\hline 13 & 1,861 & $0.33 \pm 0.35$ & $0.35 \pm 0.32$ & 922 (50\%) & 345 (19\%) & $103(6 \%)$ \\
\hline 14 & 2,361 & $0.34 \pm 0.31$ & $0.30 \pm 0.35$ & $1,259(53 \%)$ & $573(24 \%)$ & 234 (10\%) \\
\hline 15 & 2,022 & $0.50 \pm 2.9$ & $0.38 \pm 0.32$ & 923 (46\%) & $500(25 \%)$ & $318(16 \%)$ \\
\hline 16 & 15 & $0.31 \pm 0.34$ & $0.45 \pm 0.40$ & 4 (26.7\%) & $3(20 \%)$ & $2(13 \%)$ \\
\hline 17 & 764 & $0.71 \pm 0.27$ & $0.69 \pm 0.34$ & 197 (26\%) & 99 (13\%) & $62(8 \%)$ \\
\hline \multicolumn{7}{|c|}{ Category D } \\
\hline 18 & 1,841 & $0.66 \pm 0.28$ & $0.61 \pm 0.31$ & 354 (19\%) & 114 (6\%) & $35(2 \%)$ \\
\hline 19 & 578 & $0.04 \pm 0.36$ & $0.06 \pm 0.34$ & 319 (55\%) & $162(28 \%)$ & 87 (15\%) \\
\hline 20 & 718 & $0.65 \pm 0.35$ & $0.48 \pm 0.43$ & 339 (47\%) & $215(30 \%)$ & 135 (19\%) \\
\hline
\end{tabular}

RAP: Relationship Amplitude - Pressure.

\section{ICP derived indices}

The rational for introducing ICP-derived indices have been to enhance the diagnostic information of ICP monitoring [3,8]. The most commonly used such index, the correlation coefficient (R) between the ICP wave amplitude (A) and ICP (P) level (RAP), which is considered to be an indicator of the intracranial pressure volume compensatory reserve capacity $[3,6,10,14]$. The RAP should thus be of particular value in the surveillance of patients with TBI $[8,12,14,18]$, cerebral bleeds and hydrocephalus $[10,11,13]$. With an upper normal threshold level of about $+0.6[3,8,11-14]$, however, the clinical usefulness of this index remains to be determined $[4,19,20]$. One reason for this could be the erroneous ICP values being incorporated into the index value.

The RAP was originally determined from amplitudes computed using the frequency domain method $[8,14]$. In contrast, the MWA was presently determined using the time domain method [17]. Although the two methods are not equivalent with regard to computation of ICP wave amplitudes [21], how amplitudes are computed should not affect the results since amplitudes are relative values not being affected by baseline pressure. Also, the concept of RAP being an indicator of intracranial pressure reserve capacity should not be affected by the method of computing amplitudes. 

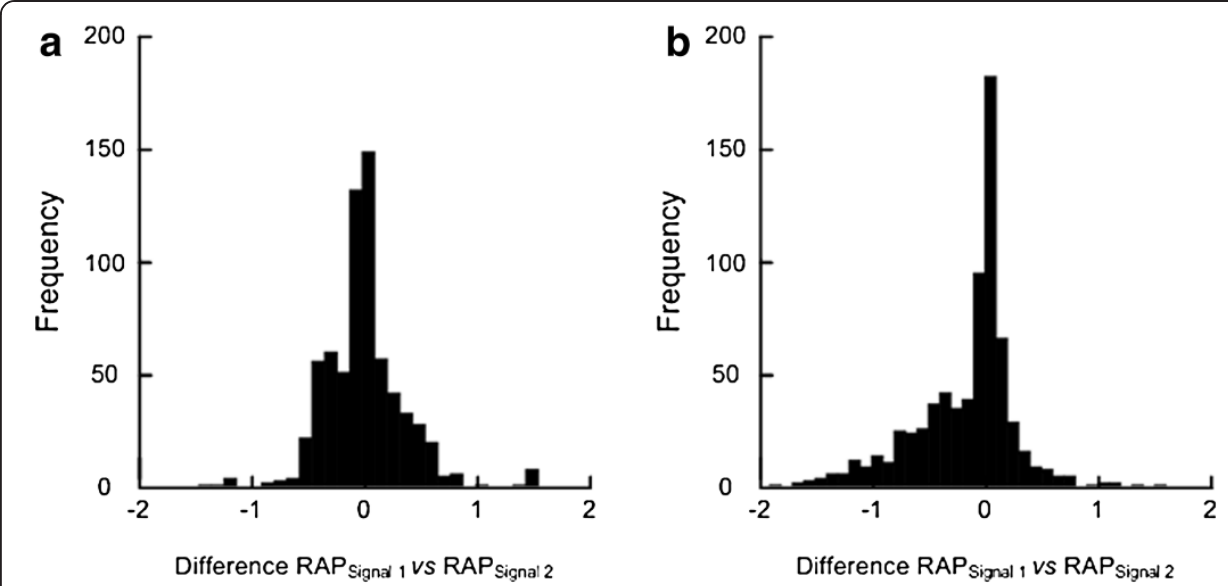

Figure 3 Histograms show frequency of differences in RAP between identical Signals 1 and 2 in patients 1 and 20. Histograms of differences in RAP between identical 4-min periods of Signal 1 and 2 are shown for PatID's 1 [a; mean difference $(+s t d)=0.02 \pm 0.36, n=685]$, and 20 [a; mean difference $(+s t d)=-0.17 \pm 0.45 ; n=718$ ]. The histograms illustrate that despite minor mean difference in RAP between Signals 1 and 2 of all 4 -min periods, the frequency of major negative and positive differences in RAP can be extensive.

\section{Measurements of differences in mean ICP between two ICP sensors}

We have previously observed markedly different mean ICP levels from two simultaneous ICP measurements $[16,22,23]$. As we recently reported in the very same ICP recordings as presented here, the differences in mean ICP occurred despite of close to identical MWAs (Patients 1-17; ref [16]; Patients 18-20, ref [22]). The fluctuations in the mean ICP were caused by spontaneous shifts and drifts of the ICP baseline pressure. As the ICP is a pressure value relative to the atmospheric pressure (representing the baseline or reference pressure), any change in baseline pressure obviously will affect the ICP level being scored.

There are three major factors related to hospital environment that may affect the ICP baseline pressure: Human factors, technical issues and technology issues. The most important human factor is erroneous zeroing of the ICP sensor, and mal-positioning of the sensor/catheter. Technical issues include sensor damage that may occur during implantation or at any point during monitoring and sensitivity to electrostatic discharges (ESD's) [15]. Moreover, when using a fluid system, loss of fluid continuity due to air bubbles and/or partial/total occlusion of the fluid catheter by blood cloths or brain tissue may cause erroneous pressure reproduction. Technology issues relate to the properties of the ICP sensor itself. For the ICP sensors used here, we have shown how the transfer function varies between solid and fluid/air pouch sensors, making the air pouch sensor less useful for reproduction of pressure waveforms [16]. All factors mentioned above may thus contribute to the observed differences in RAP.

\section{Comparison of RAP scores from two simultaneous ICP signals}

In a significant proportion of our observations, there were marked differences in RAP between Sensors 1 and 2 (Table 2). A difference in RAP $\geq 0.4$ between the two signals was hence seen in $>20 \%$ of the observations in more than half of the patients. It might be questioned whether these differences are of clinical importance. To explore this 
Table 3 Proportion of 4-min observations with RAP $<0.6$ in both signals (left), RAP $\geq 0.6$ in both signals (middle) and RAP $\geq 0.6$ in one signal while RAP $<0.6$ in another signal (right)

\begin{tabular}{|c|c|c|c|}
\hline PatID & $\begin{array}{l}\operatorname{RAP}_{\text {SIGNAL } 1}<0.6 / \\
\operatorname{RAP}_{\text {SIGNAL } 2}<0.6\end{array}$ & $\begin{array}{l}\operatorname{RAP}_{\text {SIGNAL } 1} \geq 0.6 / \\
\operatorname{RAP}_{\text {SIGNAL } 2 \geq 0.6} \geq\end{array}$ & $\begin{array}{l}\text { RAP }_{\text {SIGNAL } 1} \geq 0.6 / \text { RAP }_{\text {SIGNAL }}<0.6 \text { or } \\
\text { RAP }_{\text {SIGNAL } 1}<0.6 / \text { RAP SIGNAL } 2_{2} \geq 0.6\end{array}$ \\
\hline \multicolumn{4}{|c|}{ Category A } \\
\hline 1 & 308 (45\%) & 233 (34\%) & 144 (21\%) \\
\hline 2 & 842 (81\%) & 115 (11\%) & $83(8 \%)$ \\
\hline 3 & $21(5 \%)$ & 339 (82\%) & 54 (13\%) \\
\hline 4 & 176 (29\%) & 319 (53\%) & 109 (18\%) \\
\hline 5 & 319 (30\%) & 501 (47\%) & 245 (23\%) \\
\hline \multicolumn{4}{|c|}{ Category B } \\
\hline 6 & 95 (45\%) & 0 & 116 (55\%) \\
\hline 7 & $536(36 \%)$ & 272 (18\%) & 691 (46\%) \\
\hline 8 & 65 (24\%) & 118 (43\%) & 91 (33\%) \\
\hline 9 & 156 (82\%) & $4(2 \%)$ & 31 (16\%) \\
\hline 10 & $5(2 \%)$ & 270 (89\%) & $27(9 \%)$ \\
\hline \multicolumn{4}{|c|}{ Category C } \\
\hline 11 & $140(8 \%)$ & 1066 (58\%) & 628 (34\%) \\
\hline 12 & 4,306 (90\%) & $34(1 \%)$ & 437 (9\%) \\
\hline 13 & 1,176 (63\%) & 266 (14\%) & 419 (23\%) \\
\hline 14 & $1,542(65 \%)$ & 318 (14\%) & 501 (21\%) \\
\hline 15 & 985 (49\%) & 390 (19\%) & 647 (32\%) \\
\hline 16 & $10(67 \%)$ & $3(20 \%)$ & $2(13 \%)$ \\
\hline 17 & $116(15 \%)$ & 494 (65\%) & $154(20 \%)$ \\
\hline \multicolumn{4}{|c|}{ Category D } \\
\hline 18 & 443 (24\%) & $1,106(60 \%)$ & 292 (16\%) \\
\hline 19 & 523 (91\%) & $10(2 \%)$ & $45(8 \%)$ \\
\hline 20 & 177 (25\%) & 313 (44\%) & 228 (32\%) \\
\hline
\end{tabular}

further, we therefore determined the proportion of 4-min observations wherein the RAP was $\geq 0.6$ in one signal while $<0.6$ in another (above normal threshold level in one sensor and below in the other). Doing so, we found this setting in $>20 \%$ of scores in $12 / 20$ patients; moreover, it occurred with every type of sensor being used in the study. This observation is important because in the clinical setting, surveillance of patients is based on the actual monitoring values that are revealed to the observer (physician or nurse).

Due to erroneous ICP scores being incorporated into the RAP scores, its usefulness as a guide in the management of neurosurgical patients will be hampered. In contrast, as the ICP wave amplitude does not become affected by baseline pressure changes, the ICP wave amplitude is a robust parameter. Thus, in a recent study comparing the ICP waveforms ICP wave amplitude, ICP wave slope, and RAP as measures of intracranial compliance in head injury patients, the ICP wave amplitude showed best performance [19]. 


\section{ICP sensors}

The ICP sensors referred to in this study have been widely used for years; they thus all represent state-of-the art technology for ICP monitoring. While the Edward's fluid sensor is extensively used for monitoring of fluid-pressures in general, including arterial blood pressure, intraventricular pressure and central venous pressure, dedicated ICP sensors were represented by the solid Codman ICP sensor [24-28], the air-pouch Spiegelberg ICP sensor $[29,30]$, and the fibreoptic Camino ICP sensor [31,32].

\section{Conclusions}

Simultaneous monitoring of the ICP-derived index RAP from two separate ICP sensors reveals marked differences in the index values. The differences in RAP may be explained by erroneous scoring of the ICP level. This will hamper the usefulness of RAP as a guide in the management of neurosurgical patients.

\section{Abbreviations}

ESD: Electrostatic discharge; ICP: Intracranial pressure; MWA: Mean ICP wave amplitude; RAP: Correlation coefficient (R) between ICP wave amplitude (A) and ICP level (P); SW: Single wave; TBI: Traumatic brain injury.

\section{Competing interests}

WSO reports no conflicts of interest. PKE has financial interest in the software company (dPCom A/S) that manufactures the software (Sensometrics ${ }^{\circledR}$ Software), which was used for digital recording of the continuous pressure signals in this study.

\section{Authors' contributions}

Both authors contributed to conception and design, acquisition and interpretation of data. PKE contributed the bulk of the drafting of the manuscript and WSO contributed with thorough editing of the manuscript. Both authors have read and approved the final manuscript.

Received: 13 October 2012 Accepted: 11 February 2013

Published: 13 February 2013

\section{References}

1. Marmarou AAR, Ward JD, Choi SC, Young HF, Eisenberg HM, Foulkes MA, Marshall LF, Jane JA: Impact of ICP instability and hypotension on outcome in patients with severe head trauma. J Neurosurg 1991, 75:S59-S66.

2. Czosnyka M: Monitoring and interpretation of intracranial pressure. J Neurol Neurosurg Psychiatry 2004, 75(6):813-821.

3. Smith M: Monitoring intracranial pressure in traumatic brain injury. Anesth Analg 2008, 106(1):240-248.

4. Eide PK, Sorteberg W: Diagnostic intracranial pressure monitoring and surgical management in idiopathic normal pressure hydrocephalus: a 6-year review of 214 patients. Neurosurgery 2010, 66(1):80-91.

5. Eide PK, Bentsen G, Sorteberg AG, Marthinsen PB, Stubhaug A, Sorteberg W: A randomized and blinded singlecenter trial comparing the effect of intracranial pressure and intracranial pressure wave amplitude-guided intensive care management on early clinical state and 12-month outcome in patients with aneurysmal subarachnoid hemorrhage. Neurosurgery 2011, 69(5):1105-1115.

6. Czosnyka M, Smielewski P, Timofeev I, Lavinio A, Guazzo E, Hutchinson P, Pickard JD: Intracranial pressure: more than a number. Neurosurgical focus 2007, 22(5):E10.

7. Czosnyka M, Pickard JD: Monitoring and interpretation of intracranial pressure. J Neurol Neurosurg Psychiatry 2004, 75(6):813-821.

8. Czosnyka M, Price DJ, Williamson M: Monitoring of cerebrospinal dynamics using continuous analysis of intracranial pressure and cerebral perfusion pressure in head injury. Acta Neurochir (Wien) 1994, 126(2-4):113-119.

9. Eide PK, Sorteberg A, Bentsen G, Marthinsen PB, Stubhaug A, Sorteberg W: Pressure-derived versus pressure wave amplitude-derived indices of cerebrovascular pressure reactivity in relation to early clinical state and 12-month outcome following aneurysmal subarachnoid hemorrhage. J Neurosurg 2012, 116(5):961-971.

10. Kim DJ, Czosnyka Z, Keong N, Radolovich DK, Smielewski P, Sutcliffe MP, Pickard JD, Czosnyka M: Index of cerebrospinal compensatory reserve in hydrocephalus. Neurosurgery 2009, 64(3):494-501. discussion 501-492.

11. Schuhmann MU, Sood S, McAllister JP, Jaeger M, Ham SD, Czosnyka Z, Czosnyka M: Value of overnight monitoring of intracranial pressure in hydrocephalic children. Pediatr Neurosurg 2008, 44(4):269-279.

12. Timofeev I, Czosnyka M, Nortje J, Smielewski P, Kirkpatrick P, Gupta A, Hutchinson P: Effect of decompressive craniectomy on intracranial pressure and cerebrospinal compensation following traumatic brain injury. $J$ Neurosurg 2008, 108(1):66-73.

13. Weerakkody RA, Czosnyka M, Schuhmann MU, Schmidt E, Keong N, Santarius T, Pickard JD, Czosnyka Z: Clinical assessment of cerebrospinal fluid dynamics in hydrocephalus. Guide to interpretation based on observational study. Acta Neurol Scand 2011, 124(2):85-98. 
14. Czosnyka M, Guazzo E, Whitehouse M, Smielewski P, Czosnyka Z, Kirkpatrick P, Piechnik S, Pickard JD: Significance of intracranial pressure waveform analysis after head injury. Acta Neurochir (Wien) 1996, 138(5):531-541. discussion 541-532.

15. Eide PK, Bakken A: The baseline pressure of intracranial pressure (ICP) sensors can be altered by electrostatic discharges. Biomedical engineering online 2011, 10:75.

16. Eide PK, Holm S, Sorteberg W: Simultaneous monitoring of static and dynamic intracranial pressure parameters from two separate sensors in patients with cerebral bleeds: comparison of findings. Biomedical engineering online 2012, 11(1):66.

17. Eide PK: A new method for processing of continuous intracranial pressure signals. Med Eng Phys 2006, 28(6):579-587.

18. Czosnyka M, Citerio G: Brain compliance: the old story with a new 'et cetera'. Intensive Care Med 2012, 38(6):925-927.

19. Howells T, Lewen A, Skold MK, Ronne-Engstrom E, Enblad P: An evaluation of three measures of intracranial compliance in traumatic brain injury patients. Intensive Care Med 2012, 38(6):1061-1068.

20. Eide PK, Kerty E: Static and pulsatile intracranial pressure in idiopathic intracranial hypertension. Clin Neurol Neurosurg 2011, 113(2):123-128.

21. Holm S, Eide PK: The frequency domain versus time domain methods for processing of intracranial pressure (ICP) signals. Med Eng Phys 2008, 30(2):164-170.

22. Eide PK: Comparison of simultaneous continuous intracranial pressure (ICP) signals from a Codman and a Camino ICP sensor. Med Eng Phys 2006, 28(6):542-549.

23. Eide $\mathrm{PK}$, Sorteberg $\mathrm{W}$ : Simultaneous measurements of intracranial pressure parameters in the epidural space and in brain parenchyma in patients with hydrocephalus. J Neurosurg 2010, 113(6):1317-1325.

24. Piper IR, Miller JD: The evaluation of the wave-form analysis capability of a new strain-gauge intracranial pressure MicroSensor. Neurosurgery 1995, 36(6):1142-1144. discussion 1144-1145.

25. Gray WP, Palmer JD, Gill J, Gardner M, lannotti F: A clinical study of parenchymal and subdural miniature straingauge transducers for monitoring intracranial pressure. Neurosurgery 1996, 39(5):927-931. discussion 931-922.

26. Fernandes HM, Bingham K, Chambers IR, Mendelow AD: Clinical evaluation of the Codman microsensor intracranial pressure monitoring system. Acta neurochirurgica Supplement 1998, 71:44-46.

27. Signorini DF, Shad A, Piper IR, Statham PF: A clinical evaluation of the Codman MicroSensor for intracranial pressure monitoring. Br J Neurosurg 1998, 12(3):223-227.

28. Koskinen LO, Olivecrona M: Clinical experience with the intraparenchymal intracranial pressure monitoring Codman MicroSensor system. Neurosurgery 2005, 56(4):693-698. discussion 693-698.

29. Yau YH, Piper IR, Clutton RE, Whittle IR: Experimental evaluation of the Spiegelberg intracranial pressure and intracranial compliance monitor. Technical note. J Neurosurg 2000, 93(6):1072-1077.

30. Lang JM, Beck J, Zimmermann M, Seifert V, Raabe A: Clinical evaluation of intraparenchymal Spiegelberg pressure sensor. Neurosurgery 2003, 52(6):1455-1459. discussion 1459.

31. Piper I, Barnes A, Smith D, Dunn L: The Camino intracranial pressure sensor: is it optimal technology? An internal audit with a review of current intracranial pressure monitoring technologies. Neurosurgery 2001, 49(5):1158-1164. discussion 1164-1155.

32. Poca MA, Sahuquillo J, Arribas M, Baguena M, Amoros S, Rubio E: Fiberoptic intraparenchymal brain pressure monitoring with the Camino V420 monitor: reflections on our experience in 163 severely head-injured patients. J Neurotrauma 2002, 19(4):439-448.

33. Bland JM, Altman DG: Statistical methods for assessing agreement between two methods of clinical measurement. Lancet 1986, 1(8476):307-310

doi:10.1186/1475-925X-12-14

Cite this article as: Eide and Sorteberg: An intracranial pressure-derived index monitored simultaneously from two separate sensors in patients with cerebral bleeds: comparison of findings. BioMedical Engineering OnLine 2013 12:14.

\section{Submit your next manuscript to BioMed Central and take full advantage of:}

- Convenient online submission

- Thorough peer review

- No space constraints or color figure charges

- Immediate publication on acceptance

- Inclusion in PubMed, CAS, Scopus and Google Scholar

- Research which is freely available for redistribution 